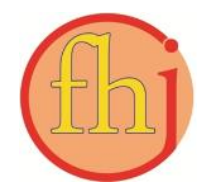

Faletehan Health Journal, 8 (2) (2021) 102-108

www. journal.Ippm-stikesfa.ac.id/ojs/index.php/FHJ

ISSN 2088-673X | e-ISSN 2597-8667

\title{
Pemanfaatan Effective Microorganisms 4 (EM4) Menggunakan Media Biofilm untuk Menurunkan Amonia dan Fosfat pada Limbah Cair Rumah Sakit
}

\author{
Sitti Badrah ${ }^{1 *}$, Resti Putri Aidina ${ }^{1}$, Andi Anwar ${ }^{1}$ \\ ${ }^{1}$ Fakultas Kesehatan Masyarakat, Universitas Mulawarman \\ *Corresponding Author: sittibadrah27@gmail.com
}

\begin{abstract}
Abstrak
Air limbah yang dihasilkan oleh kegiatan rumah sakit merupakan salah satu sumber pencemaran air yang sangat potensial karena mengandung senyawa organik yang cukup tinggi, senyawa kimia berbahaya, radioaktif, serta mikroorganisme yang berbahaya bagi lingkungan dan kesehatan. Tujuan penelitian ini untuk mengetahui perbedaan penurunan kadar amonia dan fosfat dengan pemanfaatan Effective Microorganisms 4 (EM4) menggunakan media biofilm pada limbah cair Rumah Sakit Jiwa Daerah Atma Husada Mahakam. Penelitian ini merupakan penelitian quasi experiment dengan rancangan non equivalent control group design. Sampel penelitian terdiri dari 1 bak kontrol dan 2 reaktor. Pada bak anaerob-aerob terdapat media biofilm berbahan dasar PVC. Air limbah dialirkan secara kontinyu dalam waktu tinggal 2 minggu, 3 minggu, dan 4 minggu. Hasil penelitian menunjukkan rata-rata penurunan kadar amonia dengan penambahan EM4 5\% sebesar 92,5\% dan penambahan EM4 10\% sebesar 92,1\%. Sedangkan rata-rata penurunan kadar fosfat dengan penambahan EM4 5\% sebesar 92,19\% dan penambahan EM4 10\% sebesar 65,56\%. penelitian ini secara statistik menunjukkan tidak ada perbedaan penurunan kadar amonia dengan pemanfaatan EM4 menggunakan media biofilm $(P$ value $>\alpha$ atau $0,941>0,05)$ dan ada perbedaan penurunan kadar fosfat dengan pemanfaatan EM4 menggunakan media biofilm ( $P$ value $<\alpha$ atau $0,001<0,05$ ).

Kata Kunci: Amonia, Biofilm, Effective Microorganisms 4, Fosfat
\end{abstract}

\section{The Utilization of Effective Microorganisms 4 (EM4) Using Biofilm Media to Reduce Amonia and Phosphate in Waste Water at Hospital}

\begin{abstract}
Waste water that produced by hospital activities is one of the most potential sources of water pollution because it contains high levels of organic compounds, hazardous chemical compounds, radioactivity, and microorganisms that are harmful to the environment and health. This study aims to determine the difference in decreasing ammonia and phosphate levels by utilizing Effective Microorganisms 4 (EM4) using biofilm media in waste water at Atma Husada Mahakam Mental Hospital. This research is a quasi-experimental study with non equivalent control group design. Sample of research consisted by 1 control tub and 2 reactors. In the anaerob-aerob tub, there is a PVC-based biofilm media. Waste water is flowed continuously with detention time in 2 weeks, 3 weeks, and 4 weeks. The results showed the average reduction in ammonia levels with the addition of 5\% EM4 is $92,5 \%$ and $10 \% E M 4$ is $92,1 \%$. Meanwhile, the average reduction in phosphate levels with the addition of $5 \%$ EM4 is $92,19 \%$ and $10 \%$ EM4 is $65,56 \%$. This study statistically shows there is no difference in the ammonia levels reduction ( $P$ value $>\alpha$ or $0,941>0,05)$ and there is a difference in the phosphate levels reduction ( $P$ value $<\alpha$ or $0,0001<0,05)$.

Keywords: Ammonia, Biofilm, Effective Microorganisms 4, Phosphate
\end{abstract}


Faletehan Health Journal, 8 (2) (2021) 102-108

\section{Pendahuluan}

Rumah sakit sangat berkaitan erat dengan keberadaan kumpulan manusia sehingga dapat menjadi salah satu sumber penularan penyakit hingga pencemaran lingkungan. Kondisi lingkungan rumah sakit yang tidak baik akan mempengaruhi kesehatan lingkungan yang berdampak pula terhadap timbulnya kejadian infeksi nosokomial. Hal ini diakibatkan oleh aktivitas rumah sakit yang menyebabkan limbah setiap harinya. Salah satu limbah yang dihasilkan dari kegiatan yang ada di rumah sakit adalah limbah cair. Air limbah yang dihasilkan oleh kegiatan rumah sakit merupakan salah satu sumber pencemaran air yang sangat potensial karena mengandung senyawa organik yang cukup tinggi, senyawa kimia berbahaya, radioaktif, serta mikroorganisme yang berbahaya bagi kesehatan. Oleh karena itu, potensi dampak terhadap kesehatan lingkungan maupun kesehatan masyarakat menjadi sangat besar apabila limbah cair tidak dikelola dengan baik (Kemenkes RI, 2011).

Berdasarkan Perda Provinsi Kaltim No. 02 tahun 2011 tentang Pengelolaan Kualitas Air dan Pengendalian Pencemaran Air bahwa terdapat beberapa parameter yang harus dipenuhi sebelum dibuang ke lingkungan, yaitu parameter $\mathrm{pH}$, suhu, BOD, COD, TDS, TSS, fosfat, amonia, dan bakteri koliform. Salah satu parameter tingginya pencemaran di dalam air adalah tingginya angka amonia dan fosfat. Konsentrasi amonia pada badan air mengindikasikan adanya pencemaran karena dapat menyebabkan eutrofikasi dan kematian pada mikroorganisme air. Selain itu, kadar amonia yang tinggi juga dapat menyebabkan air menjadi keruh dan memiliki bau yang tidak enak. Hal ini didasarkan pada penurunan kadar oksigen terlarut dalam badan air penerima karena oksigen yang ada digunakan untuk proses nitrifikasi NH3. Sedangkan konsentrasi fosfat yang tinggi dapat mengakibatkan ledakan pertumbuhan alga di perairan. Alga yang berlimpah ini dapat membentuk lapisan pada permukaan air, yang selanjutnya dapat menghambat penetrasi oksigen dan cahaya matahari sehingga kurang menguntungkan bagi ekosistem perairan.

Hasil penelitian, ada beberapa cara yang dapat dilakukan untuk mengolah air limbah agar memenuhi standar baku mutu sebelum dibuang ke lingkungan. Salah satu metode yang paling banyak digunakan adalah pengolahan air limbah secara biologi dengan biofilter kombinasi anaerob-aerob. Pengolahan air limbah secara biologi bertujuan untuk mengubah molekul organik yang kompleks menjadi lebih sederhana dan biomasa dengan menggunakan mikroorganisme. Pengolahan dengan cara ini juga lebih banyak dipilih karena pengoperasiannya lebih mudah dan biayanya lebih hemat(Asmadi \& Suharno, 2012). Selain itu, metode lain yang dilakukan adalah dengan menambahkan Effective Microorganisms 4 (EM4). EM4 merupakan kumpulan kultur mikroorganisme menguntungkan bersifat fermentatif yang terdiri dari bakteri fotosintetik, jamur fermentasi, bakteri asam laktat, dan ragi yang berfungsi untuk menurunkan parameter pencemar dan menekan bakteri patogen. Mikroorganisme tersebut mempunyai fungsi spesifik dan bekerjasama secara sinergis dalam menguraikan senyawa organik dan menangkap gas yang menyebabkan bau seperti $\mathrm{H}_{2} \mathrm{~S}$, amonia, dan lain-lain.

Penambahan EM4 juga terbukti mampu membantu mempercepat pertumbuhan biofilm. Hasil penelitian yang dilakukan oleh Pitriani et al. (2014) pada limbah cair di Rumah Sakit Universitas Hasanuddin Makassar, menunjukkan bahwa pengolahan sistem biofilter anaerob-aerob dengan penambahan EM4 5\% secara keseluruhan mampu menurunkan kadar BOD dan COD dengan penyisihan hingga $91,22 \%$ dan $83,26 \%$ dalam 18 hari. Penambahan EM4 mampu meningkatkan efisiensi biofilter dengan mempersingkat waktu pengolahan. Dari laporan hasil uji air limbah yang dimiliki Rumah Sakit Jiwa Daerah Atma Husada Mahakam, kadar amonia dan fosfat total setiap bulannya berada di atas standar baku mutu yang ditetapkan oleh Perda Provinsi Kaltim No. 02 tahun 2011. Data hasil uji parameter air limbah terakhir, yaitu bulan November 2018 menunjukkan kadar amonia sebesar 5,3396 mg/L dan kadar fosfat total sebesar 7,6350 mg/L, dimana standar baku mutu untuk amonia adalah $0,1 \mathrm{mg} / \mathrm{L}$ dan fosfat adalah 2 $\mathrm{mg} / \mathrm{L}$. Dari berbagai hal di atas inilah maka penulis tertarik untuk melakukan penelitian untuk menurunkan kadar amonia dan fosfat pada limbah cair Rumah Sakit Jiwa Atma Husada Mahakam dengan pemanfaatan Effective Microorganisms 4 (EM4) konsentrasi 5\% dan 10\% menggunakan media biofilm. 


\section{Metodologi Penelitian}

Penelitian ini merupakan penelitian quasi experiment dengan rancangan non equivalent control group design. Penelitian ini dilaksanakan di Rumah Sakit Jiwa Daerah Atma Husada Mahakam. Untuk pemeriksaan parameter air limbah amonia dan fosfat akan dilakukan di Global Environment Laboratory Samarinda. Sampel pretest diambil sebelum air limbah dimasukkan ke dalam reaktor berisi media biofilm dengan penambahan EM4 dan sampel postest diambil ketika air limbah sudah dilakukan pengolahan pada reaktor. Teknik pengambilan sampel menggunakan metode grab sampling (sampel sesaat), dimana pengambilan sampel ini hanya dilakukan pada satu tempat, yaitu titik outlet IPAL dan pada satu waktu tertentu saja, yaitu pada jam 09.00 - 11.00 WITA. Hal ini didasarkan pada fluktuasi debit harian ratarata air limbah rumah sakit tertinggi berada di jam tersebut (Sugito, 2013).

Prosedur percobaan sampel air limbah sebanyak masing-masing 20 liter dimasukkan ke dalam 2 reaktor perlakuan dan 1 bak kontrol. Sampel air limbah dimasukkan ke dalam bak penampungan awal, air limbah dialirkan ke dalam bak anaerob dan bak aerob. Di dalam bak anaerobaerob, dipasang media biofilm di dasar bak reaktor yang terbuat dari medium berbahan dasar $P V C$. Setelah mengalami proses penguraian material organik pada bak anaerob dan bak aerob, air limbah selanjutnya dialirkan ke bak penampungan akhir. Apabila air pada bak penampungan akhir sudah penuh, air limbah akan dipompa kembali ke bak penampungan awal menggunakan pompa air.

Proses seeding dan aklimatisasi mikroorganisme dilakukan sebelum dimasukkan ke dalam reaktor. EM4 terlebih dahulu diaktifkan dengan cara mencampurkan 1 liter EM4 dengan 5 - 10 liter air dan $5 \mathrm{sdm}$ gula merah cair. Kemudian diamkan selama $2-4$ hari dalam kondisi tertutup rapat. Proses seeding pada media biofilm dengan jenis media berbahan $P V C$ dilakukan secara alami dengan mengalirkan air limbah secara kontinyu ke dalam reaktor selama 24 jam dengan debit 0,5 $\mathrm{ml} /$ detik. Pada saat yang bersamaan EM4 yang telah diaktifkan ditambahkan ke dalam biofilm sebanyak $5 \%$ pada reaktor pertama dan $10 \%$ pada reaktor kedua. Tahap aklimatisasi dilakukan bersamaan dengan proses seeding yang merupakan proses penyesuaian diri oleh mikroorganisme agar terbiasa terhadap lingkungan barunya, yaitu limbah cair rumah sakit. Selama tahap ini dilakukan pengukuran $\mathrm{pH}$ dan suhu setiap harinya.

Proses Running air limbah dilakukan secara kontinyu selama 24 jam dengan waktu tinggal 2 minggu, 3 minggu, dan 4 minggu untuk mengamati perbedaan dari pertumbuhan biofilm setiap minggunya. Tiga waktu di atas dipilih untuk melihat perbedaan secara signifikan dari pertumbuhan bakteri pada biofilm dan efektivitasnya dalam mengurai limbah organik. Semakin lama waktu tinggal, semakin baik pertumbuhan biofilm sehingga lebih mampu mengurai polutan dalam air limbah salah satunya amonia dan fosfat. Selanjutnya dilakukan analisis menggunakan uji one way anova untuk mengetahui perbedaan secara statistik dari pengaruh variasi penambahan EM4 5\% dan 10\%.

\section{Hasil dan Pembahasan}

Hasil pemeriksaan laboratorium yang dilakukan terhadap kadar amonia dan fosfat serta pengukuran suhu dan $\mathrm{pH}$ disajikan dalam tabel berikut:

Tabel 1: Hasil Pengukuran Suhu Sampel Air Limbah

\begin{tabular}{lccc}
\hline \multirow{2}{*}{ Waktu Tinggal } & \multirow{2}{*}{ Kontrol } & \multicolumn{2}{c}{ Konsentrasi EM4 } \\
\cline { 3 - 4 } & & $5 \%$ & $10 \%$ \\
\hline Minggu 2 & $25,5^{\circ} \mathrm{C}$ & $25,7^{\circ} \mathrm{C}$ & $25,7^{\circ} \mathrm{C}$ \\
Minggu 3 & $27,1^{\circ} \mathrm{C}$ & $27,8^{\circ} \mathrm{C}$ & $27,8^{\circ} \mathrm{C}$ \\
Minggu 4 & $26,1^{\circ} \mathrm{C}$ & $26,8^{\circ} \mathrm{C}$ & $26,8^{\circ} \mathrm{C}$ \\
\hline Rata-rata & $26,2^{\circ} \mathrm{C}$ & $26,7^{0} \mathrm{C}$ & $26,7^{\circ} \mathrm{C}$ \\
\hline
\end{tabular}

Berdasarkan tabel 1 di atas, diketahui bahwa pada sampel bak kontrol suhu tertinggi berada pada minggu ketiga sebesar $27,1^{\circ} \mathrm{C}$ dan suhu terendah berada pada minggu kedua sebesar $25,5^{\circ} \mathrm{C}$ serta suhu rata-rata sebesar $26,2^{\circ} \mathrm{C}$. Kemudian pada sampel yang diberikan perlakuan EM4 5\% dan $10 \%$ memiliki suhu yang sama, yaitu suhu tertinggi berada pada minggu ketiga sebesar $27,8^{\circ} \mathrm{C}$ dan suhu terendah berada pada minggu pertama sebesar $25,7^{\circ} \mathrm{C}$, serta rata-rata suhu sebesar $26,7^{\circ} \mathrm{C}$.

Tabel 2: Hasil Pengukuran pH Sampel Air Limbah

\begin{tabular}{lccc}
\hline \multirow{2}{*}{ Waktu Tinggal } & \multirow{2}{*}{ Kontrol } & \multicolumn{2}{c}{ Konsentrasi EM4 } \\
\cline { 3 - 4 } & & $5 \%$ & $10 \%$ \\
\hline Minggu 2 & 7,4 & 8,0 & 7,7 \\
Minggu 3 & 7,6 & 8,2 & 8,2 \\
Minggu 4 & 7,3 & 8,0 & 8,2 \\
\hline Rata-rata & 7,4 & 8,0 & 8,0 \\
\hline
\end{tabular}


Faletehan Health Journal, 8 (2) (2021) 102-108 www. journal.Ippm-stikesfa.ac.id/ojs/index.php/FHJ ISSN 2088-673X | 2597-8667

Berdasarkan tabel 2 di atas, diketahui bahwa pada sampel kontrol $\mathrm{pH}$ tertinggi berada pada minggu ketiga sebesar 7,6 dan $\mathrm{pH}$ terendah berada pada minggu keempat sebesar 7,3 serta $\mathrm{pH}$ rata-rata sebesar 7,4. Kemudian pada sampel yang diberikan perlakuan EM4 5\% pH tertinggi berada pada minggu ketiga sebesar 8,2 dan $\mathrm{pH}$ terendah berada pada minggu kedua dan keempat sebesar 8,0 dengan $\mathrm{pH}$ rata-rata sebesar 8,0 . Sedangkan pada sampel yang diberikan perlakuan EM4 10\% pH tertinggi berada pada minggu ketiga dan keempat sebesar 8,2 dan $\mathrm{pH}$ terendah berada pada minggu kedua sebesar 7,7 dengan $\mathrm{pH}$ rata-rata sebesar 8,0.

Berdasarkan tabel 3 di atas, pada sampel kontrol, diperoleh kadar amonia tertinggi berada pada minggu kedua sebesar $0,25 \mathrm{mg} / \mathrm{L}$ dan kadar amonia terendah berada pada minggu keempat sebesar $<0,002 \mathrm{mg} / \mathrm{L}$ dengan rata-rata sebesar $0,175 \mathrm{mg} / \mathrm{L}$. Nilai terendah ini menandakan bahwa kadar amonia berada kurang dari atau di bawah $0,002 \mathrm{mg} / \mathrm{L}$. Kemudian pada sampel yang diberikan perlakuan dengan penambahan EM4 5\% dinyatakan bahwa kadar amonia tertinggi berada pada minggu pertama sebesar $0,21 \mathrm{mg} / \mathrm{L}$ dan kadar amonia terendah berada pada minggu keempat sebesar $0,01 \mathrm{mg} / \mathrm{L}$ dengan rata-rata sebesar 0,083 mg/L. Sedangkan pada perlakuan dengan penambahan EM4 10\% dinyatakan bahwa kadar amonia tertinggi berada pada minggu pertama sebesar $0,23 \mathrm{mg} / \mathrm{L}$ dan kadar amonia terendah berada pada minggu keempat sebesar $0,0191 \mathrm{mg} / \mathrm{L}$ dengan rata-rata sebesar 0,0907 $\mathrm{mg} / \mathrm{L}$. Persentase rata-rata penurunan kadar amonia dengan penambahan EM4 5\% sebesar 92,5\% dan pada penambahan EM4 10\% sebesar 92,1\%.

Tabel 3: Penurunan Kadar Amonia (NH3)

\begin{tabular}{ccccccc}
\hline \multirow{2}{*}{ Sebelum Perlakuan } & \multirow{2}{*}{ Waktu Tinggal } & \multirow{2}{*}{ Kontrol } & \multicolumn{4}{c}{ Konsentrasi EM4 } \\
\cline { 4 - 7 } & Minggu 2 & $5 \%$ & Persentase & $10 \%$ & Persentase \\
\hline \multirow{3}{*}{1,12} & Minggu 3 & 0,25 & 0,21 & $81,2 \%$ & 0,23 & $79,4 \%$ \\
& Minggu 4 & 0,1 & 0,03 & $97,3 \%$ & 0,023 & $97,9 \%$ \\
\cline { 2 - 7 } & Rata-rata & 0,002 & 0,01 & $99 \%$ & 0,0191 & $99 \%$ \\
\hline
\end{tabular}

Keterangan : Penyajian data di atas dalam satuan $\mathrm{mg} / \mathrm{L}$

Tabel 4: Penurunan Kadar Fosfat (PO4)

\begin{tabular}{ccccccc}
\hline \multirow{2}{*}{ Sebelum Perlakuan } & \multirow{2}{*}{ Waktu Tinggal } & \multirow{2}{*}{ Kontrol } & \multicolumn{4}{c}{ Konsentrasi EM4 } \\
\cline { 3 - 6 } & & & $5 \%$ & Persentase & $10 \%$ & Persentase \\
\hline \multirow{3}{*}{4,318} & Minggu 2 & 3,234 & 0,607 & $85,94 \%$ & 1,421 & $67,1 \%$ \\
& Minggu 3 & 3,645 & 0,335 & $92,24 \%$ & 1,967 & $54,4 \%$ \\
& Minggu 4 & 2,604 & 0,069 & $98,4 \%$ & 1,069 & $75,24 \%$ \\
\cline { 2 - 6 } & Rata-rata & 3,161 & 0,337 & $92,19 \%$ & 1,485 & $65,56 \%$ \\
\hline
\end{tabular}

Keterangan : Penyajian data di atas dalam satuan mg/L

Tabel 5: Hasil Uji One Way Anova Amonia dan Fosfat

\begin{tabular}{lccccc}
\hline & Sum of Squares & df & Mean Square & F & Sig. \\
\hline Amonia & & & & & \\
$\quad$ Between Groups & 0,002 & 2 & 0,001 & 0,062 & 0,941 \\
$\quad$ Within Groups & 0,085 & 6 & 0,014 & & \\
\hline Total & 0,087 & 8 & & & \\
\hline Fosfat & 12,101 & 2 & 6,051 & 32,882 & 0,001 \\
$\quad$ Between Groups & 1,104 & 6 & 0,184 & & \\
$\quad$ Within Groups & 13,205 & 8 & & & \\
\hline Total & & & &
\end{tabular}


Berdasarkan tabel 4, pada sampel kontrol, diperoleh kadar fosfat tertinggi berada pada minggu ketiga sebesar 3,645 mg/L dan kadar fosfat terendah berada pada minggu keempat sebesar 2,604 mg/L dengan rata-rata sebesar 3,161 mg/L. Kemudian pada sampel yang diberikan perlakuan dengan penambahan EM4 5\% dinyatakan bahwa kadar fosfat tertinggi berada pada minggu pertama sebesar 0,607 $\mathrm{mg} / \mathrm{L}$ dan kadar fosfat terendah berada pada minggu keempat sebesar $0,069 \mathrm{mg} / \mathrm{L}$ dengan rata-rata sebesar $0,337 \mathrm{mg} / \mathrm{L}$. Sedangkan pada perlakuan dengan penambahan EM4 10\% dinyatakan bahwa kadar fosfat tertinggi berada pada minggu ketiga sebesar 1,967 mg/L dan kadar fosfat terendah berada pada minggu keempat sebesar $1,069 \mathrm{mg} / \mathrm{L}$ dengan rata-rata sebesar 1,485 $\mathrm{mg} / \mathrm{L}$. Persentase rata-rata penurunan kadar fosfat dengan penambahan EM4 5\% sebesar 92,19\% dan pada penambahan EM4 10\% sebesar 65,56\%.

Berdasarkan tabel 5, diperoleh hasil uji one way anova amonia dengan nilai $\mathrm{F}$ hitung $=0,062$ dan sig $=0,941$. Dari hasil tersebut dapat diketahui bahwa nilai F hitung < F tabel, yaitu 0,062 < 5,143. Kemudian nilai sig 0,941, dengan demikian dapat disimpulkan bahwa tidak terdapat perbedaan penurunan kadar amonia dengan pemanfaatan Effective Microorganisms 4 (EM4) pada limbah cair RSJD Atma Husada Mahakam. Hasil uji one way anova fosfat dengan nilai $\mathrm{F}$ hitung $=32,882$ dan sig $=0,001$. Dari hasil tersebut dapat diketahui bahwa nilai $\mathrm{F}$ hitung > F tabel, yaitu 32,882 > 5,143. Kemudian nilai sig 0,001, dapat disimpulkan bahwa terdapat perbedaan penurunan kadar fosfat dengan pemanfaatan Effective Microorganisms 4 (EM4) pada limbah cair RSJD Atma Husada Mahakam.

\section{Pembahasan}

Penambahan EM4 dengan konsentrasi 5\% dan $10 \%$ menggunakan media biofilm menyebabkan penurunan kadar amonia dan fosfat setiap minggunya. Hasil penelitian menunjukkan bahwa kadar amonia mengalami penurunan setiap minggunya. Proses penurunan amonia disebabkan oleh mikroorganisme EM4 yang berada pada reaktor anaerob-aerob. Penambahan EM4 secara khusus bertujuan untuk menguraikan senyawa organik, seperti senyawa karbon, hidrogen, nitrogen, dan oksigen. Senyawa oganik tersebut dengan bantuan mikroorganisme kemudian diuraikan lagi menjadi senyawa organik lainnya yang lebih sederhana seperti karbondioksida dan amonia. Proses penguraian ini secara tidak langsung menurunkan kadar amonia.

Proses penurunan selanjutnya berlangsung pada bak anaerob-aerob yang juga terdapat media biofilm. Pada zona anaerob tanpa adanya bantuan oksigen, senyawa organik yang terkandung dalam air limbah yang melewati media biofilm akan tertahan dan diuraikan oleh mikroorganisme yang menempel pada biofilm tersebut. Sehingga, kandungan senyawa organik semakin berkurang yang akhirnya berpengaruh terhadap turunnya kadar amonia. Mikroorganisme menguraikan senyawa organik dalam air limbah dan menghasilkan biogas dengan gas metan serta sejumlah kecil karbondioksida, nitrogen, hidrogen, dan hidrogen sulfida. Biogas inilah yang kemudian menghasilkan bau menyengat pada amonia. Oleh karena itu, perlu pengolahan lanjutan pada bak aerob untuk menghilangkan bau dan menurunkan kadar pencemar organik yang tinggi (Kemenkes RI, 2011).

Pada zona aerob dengan adanya oksigen, nitrogen amonium akan diubah menjadi nitrit dan nitrat yang disebut sebagai proses nitrifikasi. Nitrifikasi merupakan proses penting dalam penghilangan amonia pada air limbah karena proses ini tidak lepas dari bantuan mikroorganisme. Oksidasi amonia menjadi nitrit dilakukan oleh bakteri nitrosomonas, sedangkan oksidasi nitrit menjadi nitrat dilakukan oleh bakteri nitrobacter (Kemenkes RI, 2011).

Hal ini sejalan dengan penelitian yang dilakukan oleh Fitriadi et al., (2016) bahwa mikroorganisme efektif sebagai bahan bioremediasi menggunakan 5 perlakuan dan 1 kontrol, menunjukkan bahwa setiap perlakuan mampu menurunkan konsentrasi amonia, nitrit, dan asam sulfida dengan persentase yang berbedabeda. Namun, penurunan paling tinggi ditunjukkan pada perlakuan kelima dengan penambahan mikroorganisme sebanyak $100 \mathrm{ml}$ yang dapat menurunkan konsentrasi amonia, nitrit, dan asam sulfida masing-masing sebesar $59,88 \%, 64,60 \%$, dan $19,19 \%$.

Selanjutnya, hasil penelitian juga menunjukkan adanya penurunan kadar fosfat setiap minggunya. Adanya aktivitas dari bakteri asam laktat (Lactobacillus sp) yang terdapat dalam EM4 bertugas untuk memfermentasikan senyawa organik dalam air limbah menjadi senyawa asam laktat yang berfungsi untuk mempercepat perombakan fosfat. Adanya kerjasama bakteri 
Faletehan Health Journal, 8 (2) (2021) 102-108

asam laktat dan jamur yang terkandung dalam EM4 dapat mempercepat proses penguraian senyawa organik menjadi senyawa organik yang lebih sederhana (Munawaroh, 2013).

Selain itu, adanya biofilm dengan kombinasi anaerob-aerob membuat penghilangan senyawa fosfor menjadi lebih besar. Pada zona anaerob, senyawa fosfor anorganik yang ada di dalam selsel mikroorganisme pada biofilm akan keluar yang disebabkan oleh hidrolisa senyawa fosfor. Kemudian, pada zona aerob, senyawa fosfor terlarut akan terserap atau terdifusi ke dalam mikroorganisme pada biofilm yang kemudian disintesis menjadi polifosfat dengan adanya energi dari proses oksidasi senyawa organik yang terdapat dalam air limbah. Dengan demikian, kombinasi proses biofilter anaerob-aerob ini dapat menurunkan kadar fosfat dengan baik (Kemenkes RI, 2011). Hal ini sejalan dengan penelitian yang dilakukan oleh Saputra, et al, (2019) dalam menurunkan kadar nitrat dan fosfat limbah cair pabrik kelapa sawit menunjukkan bahwa penambahan EM4 pada biofilter berpengaruh terhadap penurunan kadar nitrit dan fosfat. Dosis EM4 yang paling optimal dalam menurunkan kadar nitrat dan fosfat adalah $0,15 \mathrm{ml}$ yang mampu menurunkan nitrat dengan efisiensi penurunan sebesar $87,81 \%$ dan fosfat dengan efisiensi penurunan sebesar $97,02 \%$.

Berdasarkan hasil uji laboratorium, kadar fosfat air limbah berfluktuasi, diketahui dengan adanya kenaikan kadar fosfat di minggu ketiga. Hal ini disebabkan pada minggu ketiga terjadi peningkatan suhu dan $\mathrm{pH}$ yang cukup tinggi dibanding pada minggu kedua dan keempat. Hal ini juga berpengaruh terhadap proses perkembangbiakan mikroorganisme pada biofilm. Seperti diketahui bahwa proses perkembangbiakan biofilm dipengaruhi oleh berbagai faktor seperti $\mathrm{pH}$, suhu, ketersediaan nutrien, kecepatan aliran, luas permukaan media, dan lain-lain. Namun, kondisi suhu dan $\mathrm{pH}$ menjadi faktor yang sangat berpengaruh terhadap proses perkembangbiakan biofilm yang kemudian memberikan dampak dalam penguraian fosfat dalam air limbah.

Penambahan EM4 juga digunakan untuk mempercepat proses pembentukan dan pematangan biofilm. Dalam kondisi normal, biofilm baru mulai terlihat pada hari ke-12 dan semakin jelas pada hari berikutnya hingga mencapai waktu 5 sampai 6 minggu untuk menjadi matang sempurna. Namun, pada penelitian ini menunjukkan bahwa penambahan EM4 mampu mempengaruhi pertumbuhan biofilm. Biofilm mulai terlihat pada hari ke-8 dan semakin menebal setiap harinya hingga menjadi sangat tebal dan matang di hari ke-24. Akibat pertumbuhan biofilm yang pesat inilah, penguraian senyawa organik menjadi lebih cepat.

Namun, berdasarkan hasil uji statistik, penambahan EM4 ternyata tidak memberikan perbedaan penurunan kadar amonia air limbah. Hal ini disebabkan adanya penurunan yang cukup signifikan juga terjadi pada bak kontrol yang tidak diberi perlakuan. Kadar amonia pada bak kontrol menunjukkan angka yang hampir sama dengan kadar amonia yang ada pada reaktor perlakuan. Adanya penurunan yang cukup signifikan pada bak kontrol salah satunya disebabkan oleh oksidasi. Air limbah pada bak kontrol dibiarkan dalam kondisi terbuka sehingga kontak dengan udara dan menyebabkan proses oksidasi aerob dapat berlangsung sehingga senyawa-senyawa organik akan diubah menjadi senyawa akhir yang relatif stabil (Kemenkes, 2011). Selain itu, cuaca panas sepanjang waktu penelitian membuat suhu meningkat sehingga menyebabkan amonia menguap. Menurut Boyd C (1998), amonia juga dapat lepas ke atmosfer dengan meningkatnya kecepatan angin dan suhu. Oleh karena itu, amonia lepas dari perairan melalui proses volatilisasi (penguapan). Hal ini terjadi karena tekanan parsial gas amonia di perairan melebihi tekanan amonia di udara.

\section{Simpulan}

Berdasarkan hasil penelitian pemanfaatan Effective Microorganisms 4 (EM4) menggunakan media biofilm dengan waktu tinggal 2 minggu, 3 minggu, dan 4 minggu, ada beberapa kesimpulan yang dapat diambil diantaranya : tidak ada perbedaan penurunan kadar amonia setelah diberikan perlakuan dengan pemanfaatan Effective Microorganisms 4 (EM4) konsentrasi 5\% dan 10\% menggunakan media biofilm dengan waktu tinggal 2 minggu, 3 minggu, dan 4 minggu pada limbah cair Rumah Sakit Jiwa Atma Husada Mahakam. Ada perbedaan penurunan kadar fosfat setelah diberikan perlakuan dengan pemanfaatan Effective Microorganisms 4 (EM4) konsentrasi 5\% dan 10\% menggunakan media biofilm dengan waktu tinggal 2 minggu, 3 minggu, dan 4 minggu pada limbah cair Rumah Sakit Jiwa Atma Husada Mahakam dengan $P$ value $=0,001$. 


\section{Referensi}

Asmadi, \& Suharno. (2012). Dasar-dasar Teknologi Pengolahan Air Limbah. Kanisius.

Boyd, C. . (1998). Water Quality for Pond Aquaculture. Auburn University.

Fitriadi, R., Dan Churun A'in Program, H., Manajemen, S., Perairan, S., Perikanan, J., Perikanan, F., \& Kelautan, I. (2016). Efektivitas Mikroorganisme Sebagai Bahan Bioremediasi Pada Limbah Pencucian Ikan Tongkol (Auxis thanzard) (Skala Laboratorium). Indonesian Journal of Fisheries Science and Technology (IJFST) Saintek Perikanan, 12(1), 52-59.

Seri Sanitasi Lingkungan Pedoman Teknis Instalasi Pengolahan Air Limbah dengan Sistem Biofilter Anaerob Aerob pada Fasilitas Pelayanan Kesehatan, (2011).

Pitriani, Daud, A., \& Jafar, N. (2014). Efektivitas Penambahan EM4 Pada Biofilter AnaerobAerob dalam Pengolahan Air Limbah RS. UNHAS.

Saputra, A., Harahap, S., \& Purwanto, E. (2019). Pengaruh Pemberian EM4 (Effective Microorganisms-4) dalam Biofilter untuk Menurunkan Kadar Nitrat dan Fosfat Limbah Cair Pabrik Kelapa Sawit.

Sugito. (2013). Aplikasi Instalasi Pengolahan Air Limbah Biofilter Untuk Menurunkan Kandungan Pencemar Bod, Cod Dan Tss Di Rumah Sakit Bunda Surabaya. Jurnal Waktu, 978, 1-7. 